\title{
34. METEOR MASS DISTRIBUTION FROM UNDERDENSE-TRAIL ECHOES
}

\author{
M. ŠImEK and B. A. McINTOSH \\ (Astronomical Institute of the Czechoslovak (National Research Council, Ottawa, \\ Academy of Sciences, Ondřejov, \\ Canada) \\ and National Research Council, Ottawa, \\ Canada)
}

\section{A BSTRACT}

The amplitude of meteor echoes is recorded on a logarithmic scale by a high-power radar equipment $\left(\lambda=9.2 \mathrm{~m}, P_{T}=3 \mathrm{MW}, G=5.6\right)$ at Springhill Meteor Observatory near Ottawa. The smallest amplitude measured corresponds to a pulse power of $10^{-12} \mathrm{~W}$, which represents a minimum electron line density of about $7 \times 10^{11} \mathrm{el} / \mathrm{m}$ or a radio magnitude of +10 .

Distribution curves of number of echoes as a function of echo power have been obtained from some 50 samples of 500 meteors each, at various times of day on about 1 day per month. The slopes showed little variation throughout the year. The statistical error in the slope value for any one sample was small, $\sim 2-3 \%$. However, determination of the mass index $s$ from these slopes involves several problems. On the basis of simplest theory we have obtained for the sporadic background,

$$
s=2 \cdot 35 \pm 0 \cdot 1
$$

with no definite seasonal or diurnal variation.

During shower periods, lower values of $s$ were obtained. For the 1966 Leonids, $s$ for the shower was determined by estimating the percentage of shower meteors in the total sample. A value $s=1 \cdot 7+0 \cdot 1$ was obtained as the mean of 6 samples. It is not known to what extent the height-ceiling effect influences the observation of this shower.

The number of meteoroids entering the Earth's atmosphere increases rapidly toward smaller sizes. It is desirable to know the exact variation of numbers with mass. Photographic observations provide the most accurate determination of the mass distribution down to about 4th magnitude. Although it is possible to observe meteors with radar over a very wide range of magnitudes, there are many difficulties in interpreting the data from brighter meteors, $M<5$ (McIntosh, 1968). In this paper we present a preliminary report on a determination of the mass distribution from measurements on underdense-trail echoes in the range approximately $5<M<10$.

The amplitude of meteor echoes is recorded on a logarithmic scale by a high-power radar equipment $\left(\lambda=9 \cdot 2 \mathrm{~m}, P_{T}=3 \mathrm{MW}, G=5 \cdot 6\right)$ at Springhill Meteor Observatory near Ottawa. An example of the record is shown in Figure 1. Typical underdense echoes may be seen at ranges of $115,130,120$, and $245 \mathrm{~km}$. The exponential decay of the echoes appears as a linear decrease in signal because of the logarithmic characteristic of the receiver. If the value of diffusion coefficient is known as a function of 

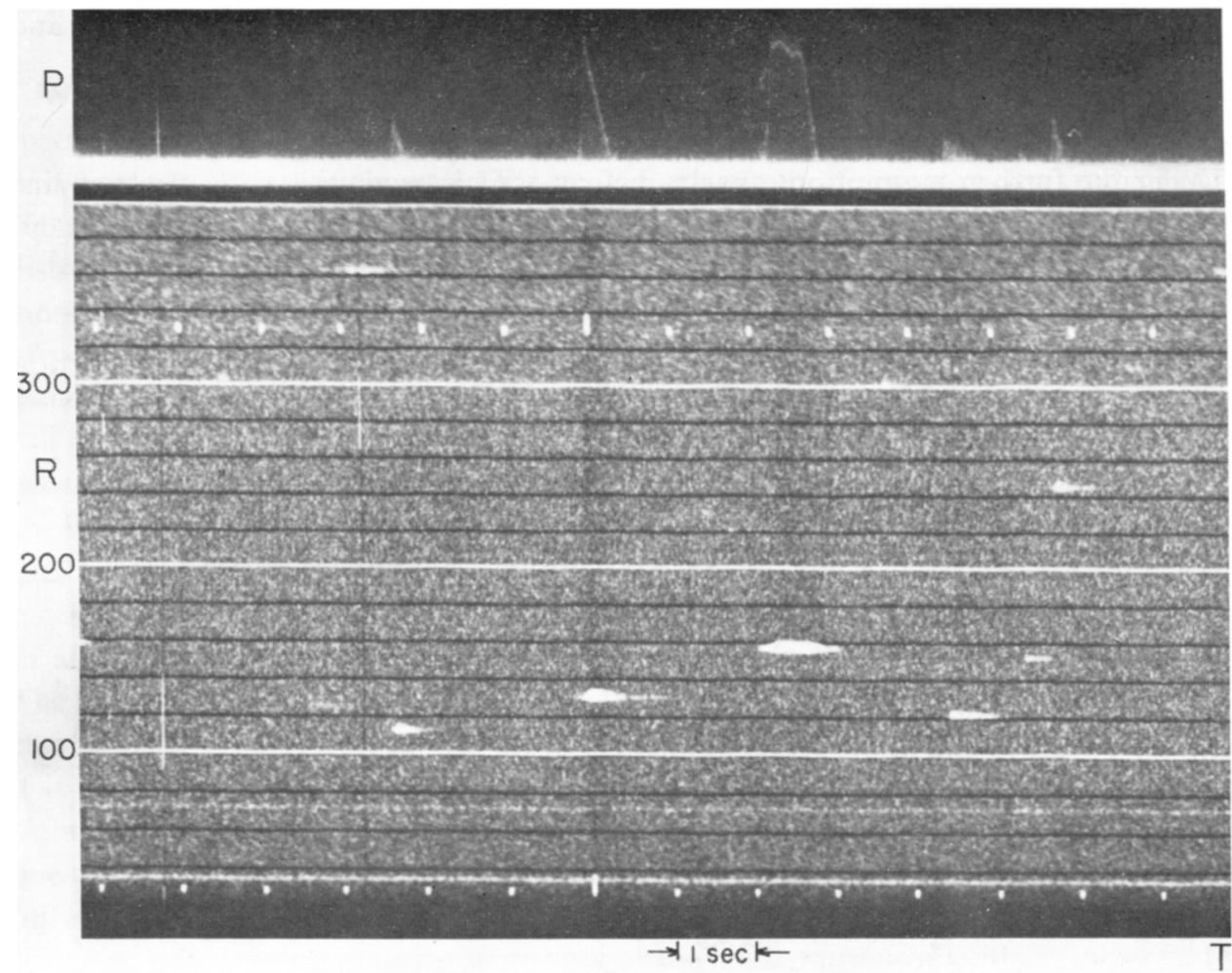

FIG. 1. Sample of record from the Ottawa meteor radar (high-power) near $00^{h}$ on January 12, 1967. Range $(R)$ scale is in kilometres. Amplitude $(P)$ scale is logarithmic and encompasses echoes at ranges 70 to $270 \mathrm{~km}$.

height, the heights of these echoes may be determined from the decay rates. The shape of the echo at $160 \mathrm{~km}$ identifies it as overdense. Underdense echoes were selected on the basis of shape.

Only echoes having amplitudes more than about 3 decibels above the noise were taken. For example, the echo in Figure 1 at $150 \mathrm{~km}$ was not used. The smallest amplitude measured corresponds to a pulse power of $10^{-12} \mathrm{~W}$. This represents a minimum electron line density of about $7 \times 10^{11} \mathrm{el} / \mathrm{m}$ or a radio magnitude of +10 .

\section{Theory}

It is assumed that the number of particles having masses between $m$ and $m+\mathrm{d} m$ may be represented by

$$
\mathrm{d} N \propto m^{-\mathrm{s}} \mathrm{d} m .
$$


Then assuming that $s$ is a constant, the number of particles $N_{m}$ having mass $m$ and greater, is

$$
N_{m} \propto m^{-(s-1)} .
$$

Under the further assumptions that a meteor trail is produced with electron line density $q \propto m$ and that received echo power $P_{R} \propto q^{2}$,

$$
N_{m} \propto P_{R}^{-(s-1) / 2} .
$$

Since the response characteristic of the receiver is logarithmic, a linear deflection $d$ was measured, where

$$
K d=10 \log P_{R} .
$$

$K$ is a calibration constant in decibels per unit deflection. Finally, one may write

$$
\log N_{m}=\text { constant }-(s-1) \frac{K}{20} d .
$$

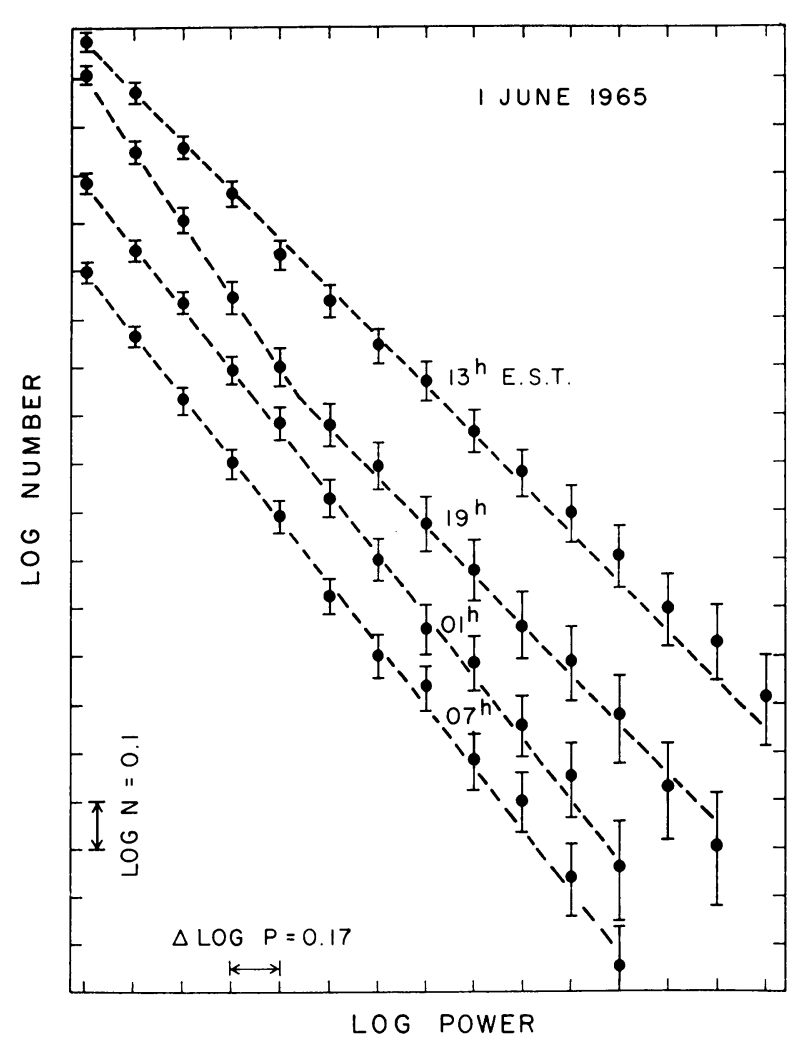

FIG. 2. Logarithm of the number of echoes (N) versus logarithm of the echo power level down to which count is made. Dispersion bars drawn equal to $V^{\prime} N$. 


\section{Observations}

We have attempted to obtain a sample of 500 meteors for each of four periods spaced 6 hours apart through one day. It is hoped to do at least one day per month. A typical set of data is shown in Figure 2. Each group of points results from about 500 echoes but they have been shifted vertically to space them. It is apparent that the distribution of amplitudes at $01^{\mathrm{h}}$ and $07^{\mathrm{h}}$ are very similar. The group at $13^{\mathrm{h}}$ contains more large particles, which may be attributed to the daytime showers at this time of year. The data for $19^{\mathrm{h}}$ illustrate one of the quirks which appeared occasionally a sudden change in the amplitude distribution.

Two methods were used to determine $s$. First, a straight line was fitted by the least-square method to those points deemed to represent the linear portion of the data. Curvature toward the high-amplitude count occurred frequently. Because choosing the 'linear' portion involved a subjective judgement, we also applied a completely mechanical method. A second-order polynomial was fitted to a fixed number of points in all cases. Each point was weighted proportional to the number of observations. The first-order coefficient was taken as the best representation of the slope of the curves. A set of observations with the two fitted lines is shown in Figure 3. Subjectively it is apparent that the straight line is the better fit over the low-amplitude values. Values of $s$ calculated by both methods are listed in Table 1. It is apparent that the linear values (method I) have less scatter. The quoted errors were calculated as follows: From the slope of the least-squares fit the $2 \sigma$ value was taken as the error to allow for unknown observational errors. For the intercomparison of the results of any one day this would be the error to be used. For observations obtained months or years apart the value of the calibration constant, $K$, varied by $\pm 5 \%$. Hence this error was included in the values listed in Table 1. It is apparent that in many cases the errors of interpretation, that is, the difference between $s$ determined by method I and method II, are greater than the 'experimental' error. In spite of this the average value of $s$ for the 27 non-shower periods is

$$
\begin{aligned}
& s=2 \cdot 35, \text { method } \mathrm{I} ; \\
& s=2 \cdot 36, \text { method II . }
\end{aligned}
$$

The associated errors are listed in Table 1. In further discussion we will use only the values determined by method $\mathrm{I}$.

\section{Trends}

Possible diurnal variation in $s$ is illustrated by Figure 4 . The April set shows little variation among the 4 periods. The May, June, and September sets include low values of $s$ attributable in the first two months to known showers and in September to a suspected shower. No definite diurnal variation has been detected in the non-shower periods. 


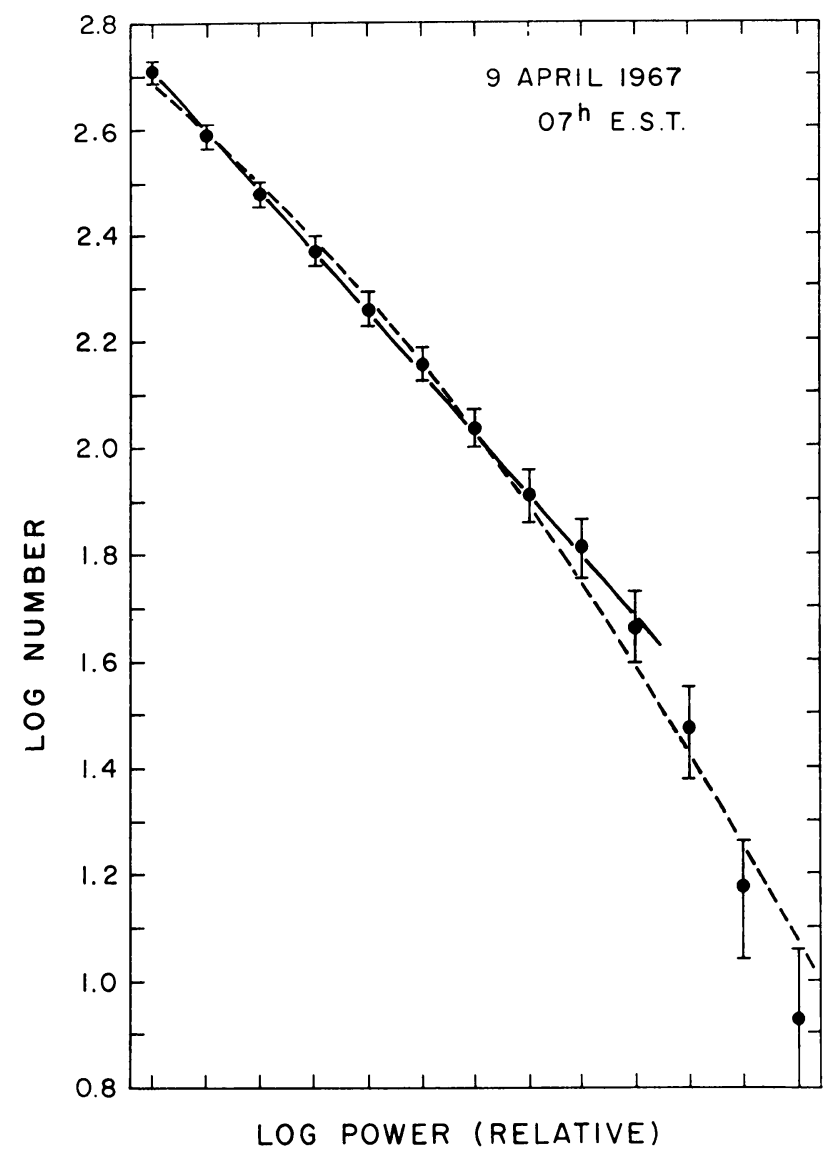

Fig. 3. Example of the two types of curve fitted to observed $\log N v s . \log P$ data. Solid line: linear relation fitted to selected number of points; broken curve: second order polynomial.

It is apparent from Figure 5 that for non-shower meteors, $s$ varies little through the year. There may be a slight trend toward higher values in Autumn, but a horizontal straight line through all the points is not unwarranted. We hope to fill in the gaps in this diagram at a later date.

\section{Shower Periods}

During shower periods, lower values of $s$ were obtained. Data from the 1966 Leonids are presented in Figure 6. It is seen that $s$ (for all echoes: shower plus background) changes in good agreement with the zenith distance of the radiant. During the peak period, rates were so high that it was impossible to read the amplitude record. 


\section{Table 1}

E.S.T.

year month day hour Count

$\begin{array}{lllll}67 & 01 & 12 & 00 & 510\end{array}$

$\begin{array}{ll}07 & 527\end{array}$

$\begin{array}{llll}67 & 02 & 10 & 01\end{array}$

07

$\begin{array}{llll}67 & 03 & 09 & 01\end{array}$

$\begin{array}{llll}67 & 04 & 11 & 07\end{array}$

07

$19-512$

$\begin{array}{llll}67 & 05 & 07 & 01\end{array}$

$01 \quad 512$

$07^{\mathrm{a}} \quad 545$

$13^{\mathrm{a}}$

19

$\begin{array}{lll}65 & 06 & 01\end{array}$

$01 \quad 531$

$07 \quad 524$

$13^{\mathrm{a}} \quad 527$

$19 \quad 512$

$\begin{array}{lllll}65 & 09 & 28 & 01 & 475\end{array}$

$07 \quad 586$

$13^{\mathrm{a}} \quad 519$

$19 \quad 471$

$\begin{array}{lllll}66 & 11 & 10 & 01 & 490\end{array}$

$07 \quad 489$

$13 \quad 497$

$19 \quad 501$

$\begin{array}{llll}66 & 11 & 17 & 00^{\text {a }}\end{array}$

$02^{\mathrm{a}}$

$04^{\mathrm{a}}$

$05^{\mathrm{a}}$

$09^{a}$

$11^{\mathrm{a}}$

66

$$
12
$$$$
\begin{aligned}
& 15 \\
& 22^{\mathrm{a}}
\end{aligned}
$$

12 $22^{\mathrm{a}}$

$00^{\mathrm{a}}$

$02^{\mathrm{a}}$

$04^{\mathrm{a}}$

$06^{\mathrm{a}}$

$08^{\mathrm{a}}$

13
501
495

497

496

483

477

493

373

456

478

521

510

511

510

508

13326

7508

20834 total.

Non-shower average $s$

R.M.S. difference Method I - Method II = 0.24.

\begin{tabular}{ccc}
\multicolumn{4}{c}{ Mass exponent $s$} \\
Method I & Method II
\end{tabular}

error

$2 \cdot 41$

$2 \cdot 38$

$0 \cdot 12$

$2 \cdot 26$

$0 \cdot 16 \quad 2 \cdot 04$

$0 \cdot 19$

$2 \cdot 43$

0.13

$0 \cdot 17$

$2 \cdot 30$

$0 \cdot 14$

$2 \cdot 28$

$0 \cdot 21$

$2 \cdot 35$

$2 \cdot 31$

0.11

$2 \cdot 34$

$0 \cdot 34$

$2 \cdot 36$

$0 \cdot 23$

\subsection{6}

$0 \cdot 11$

0.20

$0 \cdot 12$

0.19

2.27

0.13

$2 \cdot 28$

0.31

0.11

2.38

0.15

2.35

2.37

0.16

2.38

0.27

$0 \cdot 15$

0.28

0.13

$2 \cdot 01$

0.28

2.30

0.14

0.22

$2 \cdot 40$

$2 \cdot 19$

0.14

$2 \cdot 16$

0.21

0.13

2.34

2.08

$0 \cdot 10$

$\mathbf{0} \cdot 18$

$2 \cdot 21$

$0 \cdot 15$

$2 \cdot 17$

$0 \cdot 15$

$2 \cdot 48$

0.13

2.53

$0 \cdot 24$

2.48

0.14

2.53

0.22

$2 \cdot 14$

0.11

$2 \cdot 63$

0.21

$2 \cdot 40$

2.47

$2 \cdot 41$

$0 \cdot 17$

2.36

$0 \cdot 16$

0.14

2.95

$0 \cdot 20$

0.21

$\begin{array}{ll}0.15 & 2.69\end{array}$

$0 \cdot 17$

2.20

$0 \cdot 12$

$0 \cdot 25$

$2 \cdot 46$

$0 \cdot 16$

2.54

0.28

2.32

2.25

$0 \cdot 15$

$2 \cdot 86$

$0 \cdot 18$

$0 \cdot 15$

2.00

$0 \cdot 23$

0.11

1.95

$0 \cdot 18$

$2 \cdot 48$

0.14

$0 \cdot 16$

$0 \cdot 15$

2.05

$0 \cdot 17$

$2 \cdot 24$

$0 \cdot 10$

$2 \cdot 14$

$0 \cdot 18$

$2 \cdot 14$

$2 \cdot 15$

0.09

2.05

$0 \cdot 16$

$0 \cdot 11$

$0 \cdot 16$

$2 \cdot 07$

$0 \cdot 10$

2.07

$0 \cdot 12$

$2 \cdot 27$

$0 \cdot 13$

1.98

$0 \cdot 21$

2.33

$0 \cdot 11$

$2 \cdot 14$

$0 \cdot 21$

$2 \cdot 13$

0.14

$2 \cdot 18$

$0 \cdot 20$

2.33

$0 \cdot 10$

$0 \cdot 16$

$2 \cdot 30$

0.12

$2 \cdot 31$

$0 \cdot 23$

$2 \cdot 18$

$0 \cdot 11$

$2 \cdot 32$

$0 \cdot 19$

$2 \cdot 27$

$0 \cdot 10$

$2 \cdot 27$

$0 \cdot 17$

$2 \cdot 38$

$0 \cdot 11$

$2 \cdot 22$

$0 \cdot 21$

$2 \cdot 30$

$0 \cdot 17$

$2 \cdot 48$

$0 \cdot 19$

total echoes non-shower periods.

$2 \cdot 67$

$2 \cdot 36 \div 0 \cdot 25$

Notes:

a Showers or suspected showers.

" Count terminated after one hour. 


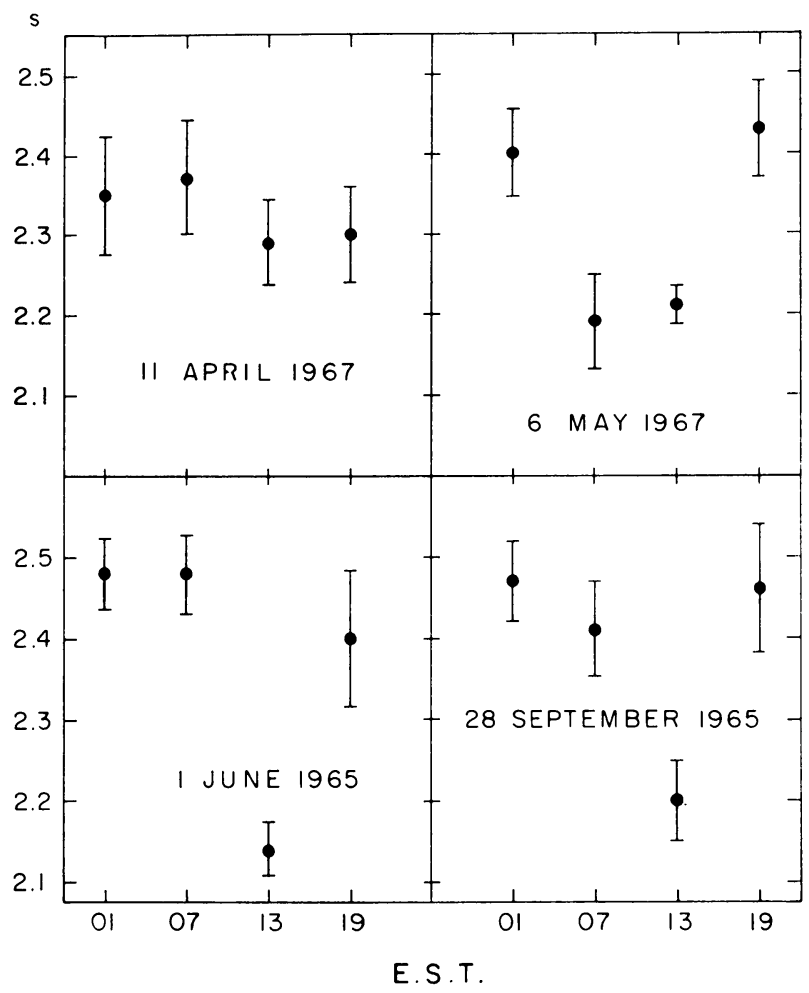

Fig. 4. Four typical sets of values of mass exponent s.

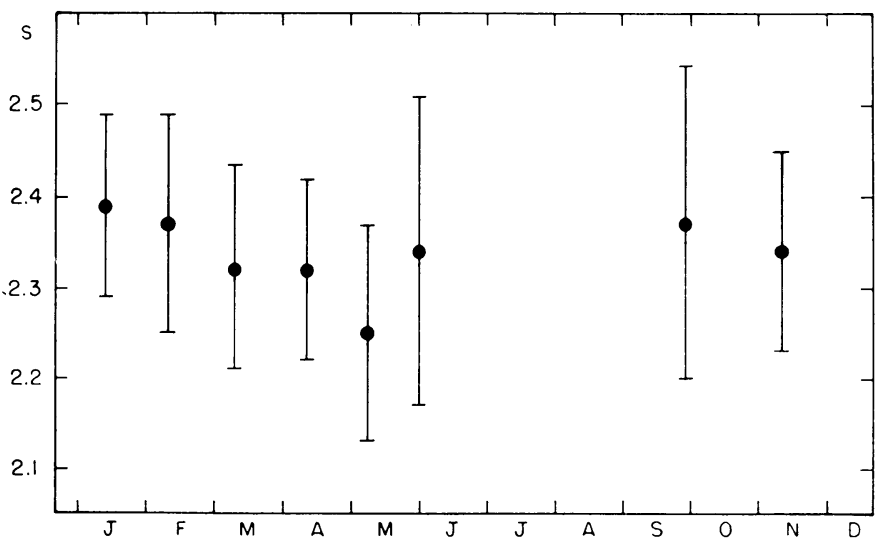

FiG. 5. Average values of mass exponent s that have heen obtained to date. 


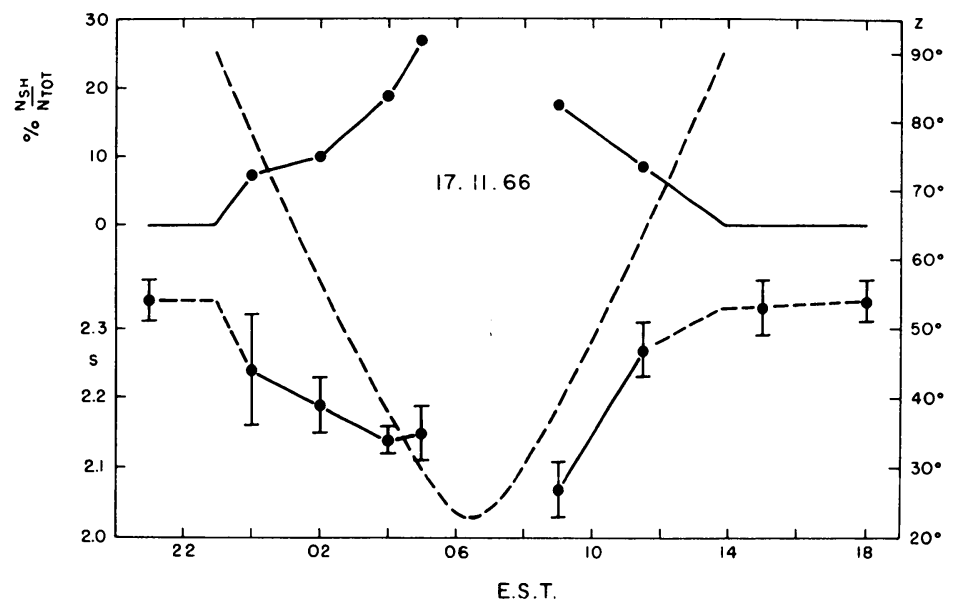

FIG. 6. Variation of mass exponent $s$ during the 1966 Leonid shower. Dashed curve shows zenith distance, $z$, of the radiant. Upper part of diagram is percent of shower echoes in total count.

For the shower, $s$ was determined by estimating the percentage of shower meteors in the total count. A value $s=1 \cdot 7 \pm 0 \cdot 1$ was obtained as the mean of 6 samples. This is considerably lower than the value $s=2 \cdot 2 \pm 0 \cdot 2$ obtained by McIntosh (unpublished) for larger particles (overdense trails). Although it cannot be proved that this is not a real change in the mass distribution, it is suspected that the so-called height-ceiling influences observation of this shower.

The variation of $s$ during a portion of the Geminid shower is shown in Figure 7. There is no correlation with position of the radiant, which may result from either of two different situations: (1) there are no Geminids in this mass range or (2) there are Geminids but their mass distribution is identical to that of the sporadic background.

For the other showers during which we have at least one period of data - Eta Aquarids May 6, Zeta Perseids and Arietids June 1, unnamed shower Sept. 28 - low values of $s$ were obtained, but we have not been able to deduce $s$ for the shower alone because of the difficulty of isolating the shower meteor echoes.

\section{Discussion}

A few of the values of $s$ obtained by other authors have been plotted in Figure 8 . The most widely accepted value for brighter meteors is $s=2.34$ obtained by Hawkins and Upton (1958) from photographic data. The recent careful analysis of visual data by Kresáková (1966) yields $s=2.35$ with no sign of change at 5th magnitude. For meteors fainter than 5th magnitude, most authors favour lower values of $s$ ranging from 2.0 to 2.2 (Kaiser, 1961; Öpik, 1955, 1958; Bronšten, 1936; Millman, 1959). Greenhow and Hall (1960) believed that sufficient account had not been taken of the 


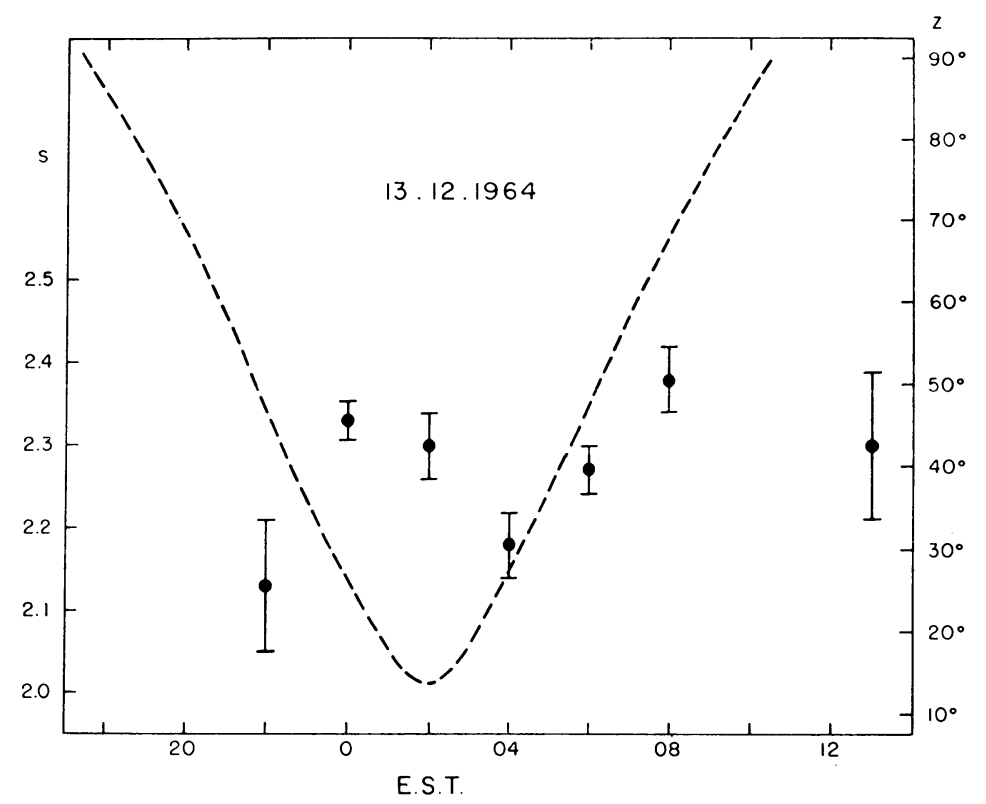

Fig. 7. Mass exponent s on December 13, 1964 (Geminid shower). Dashed curve shows zenith distance, $z$, of the radiant.

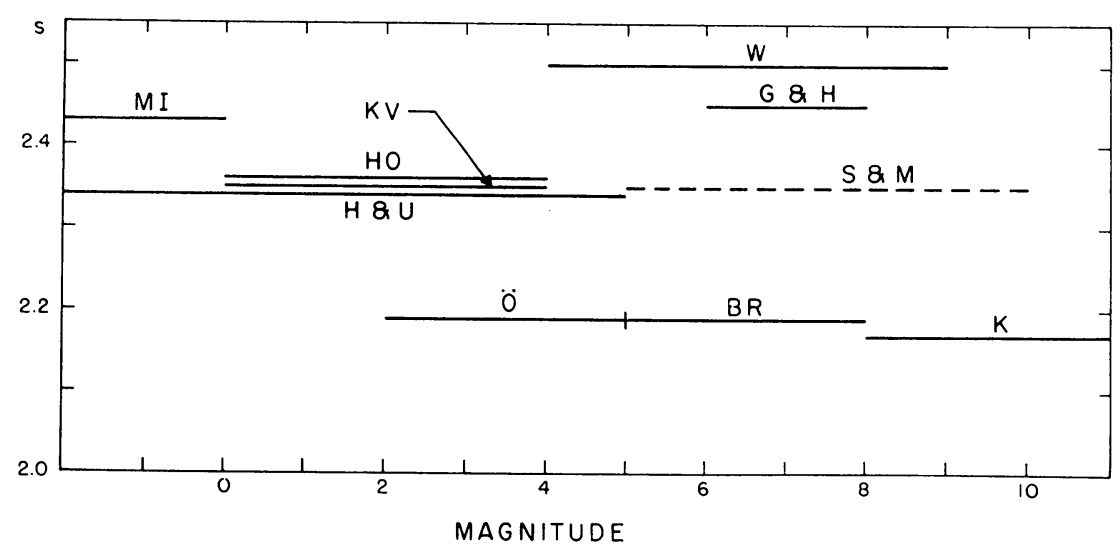

FIG. 8. Comparison of values of mass exponent $s$. $B R=$ Bronšten (1936); $G \& H=$ Greenhow and Hall (1960); $H \& U=$ Hawkins and Upton (1958); HO =Hoffmeister (1931); $K=$ Kaiser (1961); $K V=$ Kresáková (1966); $M I=$ Millman (1959); $\ddot{O}=\ddot{O p i k}(1958) ; S \& M=$ Simek and McIntosh, this paper; $W=$ Watson (1937). 
height-ceiling effect, and that $s$ lay closer to $2 \cdot 4$ for faint meteors. Our results indicate that a value of $s=2 \cdot 35$ is applicable right down to 10th magnitude.

The radar measures down to a fixed threshold in electron line density but this does not mean a fixed minimum mass. Assuming that the ionization probability $\beta \propto V^{4}$, it follows that

$$
m_{\min } \propto \frac{q_{\min }}{V^{4}}
$$

Since the mean velocity of the observed meteors varies with time of day and with season of the year, the mass threshold varies accordingly. The velocity variation will also be reflected in the height distribution of meteors. Since we have measured the decay constant as well as the amplitude of each meteor it is possible to obtain the height distribution. The two samples plotted in Figure 9 show significantly lower heights in Spring than in the Fall. The lack of any positive diurnal or seasonal variation in $s$ leads us to conclude that for sporadic meteors, velocities and heights are such that the height ceiling has no significant effect. It is only with very high velocity meteors

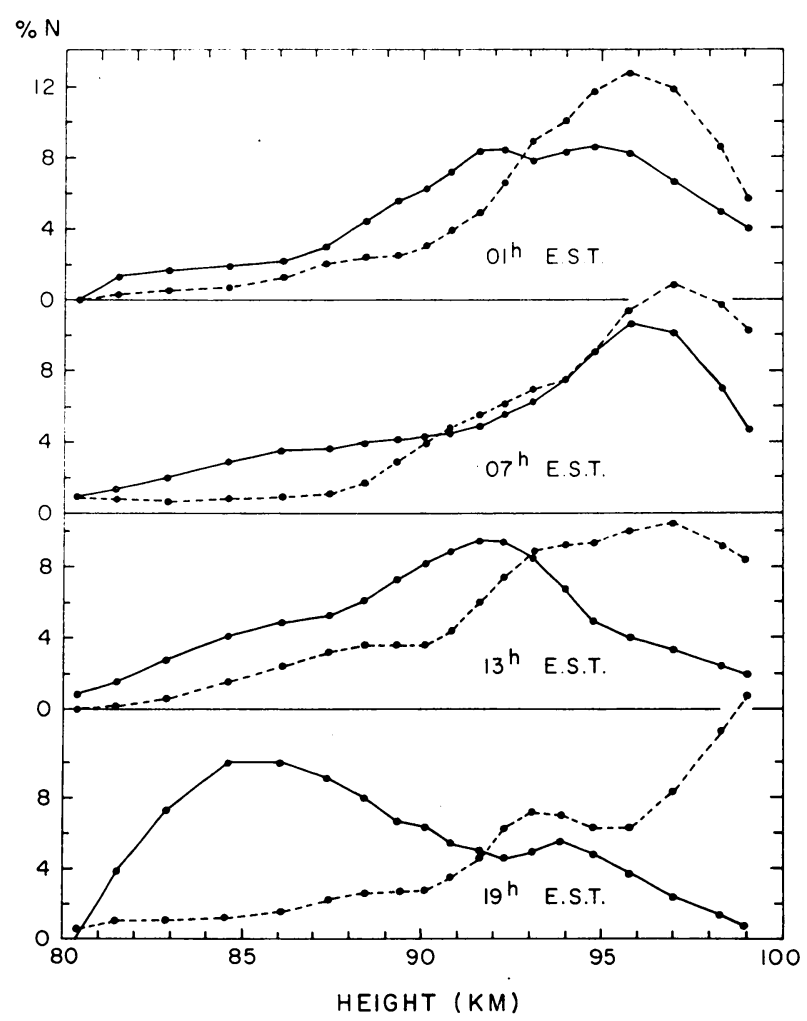

FIG. 9. Echo height distribution as determined from decay rates. Solid curves: April 1967; broken curves: September 1965. 
such as those of the Leonid shower that there may be some effect. Even here the evidence is not positive.

\section{Acknowledgement}

One of us (M.Š.) is indebted to the National Research Council of Canada for the award of a Postdoctorate Fellowship which has enabled him to carry out this work. $\mathrm{He}$ is grateful to Dr P. M. Millman for his interest during the progress of this work.

\section{References}

Bronšten, V.A. (1936) $\quad$ Astr. Zu., 13, 538.

Greenhow, J.S., Hall, J.E. (1960) Mon. Not. R. astr. Soc., 121, 183.

Hawkins, G.S., Upton, E. K.L. (1958) Astrophys. J., 128, 727.

Hoffmeister, C. (1931) Veröff. Sternw. Babelsberg, 19, 22.

Kaiser, T.R. (1961) Mon. Not. R. astr. Soc., 123, 265.

Kresáková, M. (1966) Contr. Astr. Obs. Skalnaté Pleso, 3, 75.

McIntosh, B.A. (1968) in the present volume, p. 343.

Millman, P.M. (1959) Can. Aeronaut. J., 5, 358.

Öpik, E. (1955) Mem. Soc. R. Sci. Liège, Ser. 4, 15, 125.

Öpik, E. (1958) Contr. Armagh Obs., No. 26.

Watson, F. G. (1937) Ann. Harv. Coll. Obs., 105, 623.

\section{DISCUSSION}

Elford: How was the height determined?

Simek: The heights were determined from the decay rate of underdense echoes.

Glöde: If the decay time is used, the data refer to a certain air density which may correspond to different heights throughout the year. 